\title{
A Study on the Arable Land Demand for Food Security in China
}

\author{
Aiqi Chen ${ }^{1,2}$, Huaxiang $\mathrm{He}^{3}{ }^{-}$, Jin Wang ${ }^{1,2}$, $\mathrm{Mu} \mathrm{Li}^{1,2}$, Qingchun Guan ${ }^{1,2}$ and Jinmin Hao ${ }^{1,2, *}$ \\ 1 College of Land Science and Technology, China Agricultural University, Beijing 100193, China \\ 2 Key Laboratory of Agricultural Land Quality, Ministry of Natural Resources of the People's Republic of \\ China, Beijing 100193, China \\ 3 State Key Laboratory of Simulation and Regulation of Water Cycle in River Basin, China Institute of Water \\ Resources and Hydropower Research, Beijing 100038, China \\ * Correspondence: jmhao@cau.edu.cn
}

Received: 23 July 2019; Accepted: 29 August 2019; Published: 1 September 2019

check for updates

\begin{abstract}
Food security is the basis of social stability and development. Maintaining sufficient amounts of arable land is essential for China's food security. In this paper, we consider the relationship between arable land demand to grain demand and production capacity. The changes in national population, grain production, and consumption from 2000 to 2015 are analyzed. Then, we forecast the respective possible changes in the future and accordingly forecast the arable land demand in different possible situations. The results show that the pressure to maintain sufficient amounts of arable land in 2030 may be greater than that in 2040.The higher pressure is due to larger population and lower production capacity. To ensure food security in China, we insist on maintaining 120 million ha of arable land, the "red line" for food security, and improve the arable land productivity to ensure domestic production and self-sufficiency. In addition, residents should be guided to cultivate sound food consumption habits in order to control per capita grain demand. Lastly, we should also make full use of international resources and markets to relieve the pressure on domestic resources and environments.
\end{abstract}

Keywords: arable land demand; grain demand; grain production; food security; China

\section{Introduction}

China's food security has been a global issue, especially since the publication of Lester K. Brown's book, "Who Will Feed China?" [1]. China is the most populous country with only $7 \%$ of the arable land in the world to feed about $19 \%$ of the population. People all over the world focus on the problem of food security in China. In recent years, grain production in China has increased significantly, as has the grain import. Figure 1a shows that the output of grain from 2000 to 2003 fluctuated within a tight range and increased year after year until 2015 by an average growth rate of $3.13 \%$. Figure $1 \mathrm{~b}$ shows that grain imports rose sharply in 2003, when China became a net importer. This also means that the grain self-sufficiency ratio of China has been declining. 


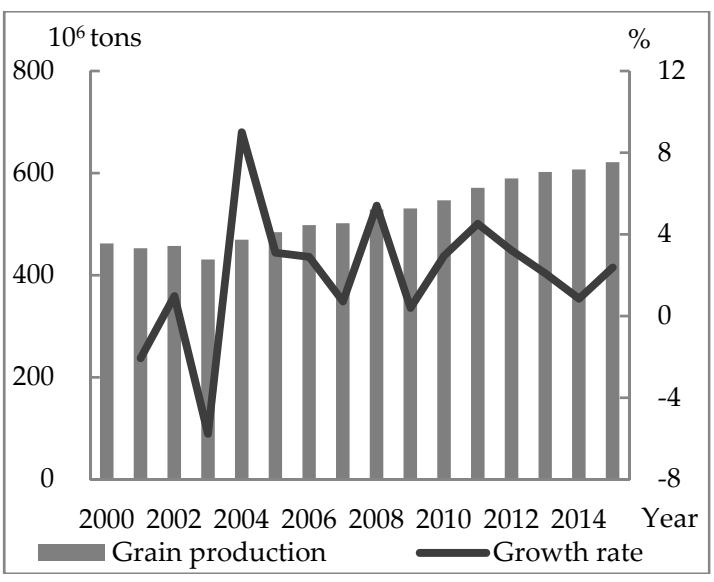

(a) Grain production

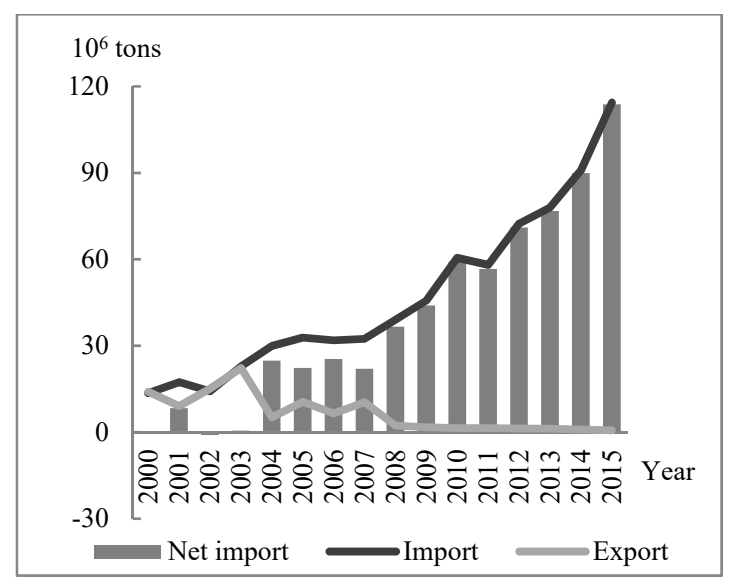

(b) Grain import and export

Figure 1. Changes in grain production and trade in China from 2000 to 2015.

Arable land is an essential part of land resources, directly affects the food security of any region. The amount of arable land in China, especially the high-quality arable land, has decreased because of rapid urban expansion, adjustments in agriculture, natural disasters, and so on. According to China land and resources statistical yearbooks, more than $75 \%$ of the reduction of arable land is annually occupied for the nonagricultural construction. Figure 2 shows that the arable land area decreased by 385.9 thousand ha from 2009 to 2015. According to the grain yield per unit area in 2015, 2.1 million tons of grain was lost, which could feed 4.2 million residents. According to the results of the Investigation and Assessment of Arable Land Quality Grade in China in 2015, the high-quality arable land accounts for $29.47 \%$ and the rest, more than two-thirds of arable land, is low-and medium-quality. Therefore, faced with an increasing population, increasing grain demand, and decreasing and not high-quality arable land, more attention should be paid to arable land protection and long-term food security. It is key to protect the quantity, quality, and ecology of arable land. As a popular Chinese saying goes, the Chinese should hold the rice bowl firmly in our own hands and protect arable land just as they protect the panda. Therefore, the Chinese government should establish and adhere to the strictest rules for protecting and economizing arable land.

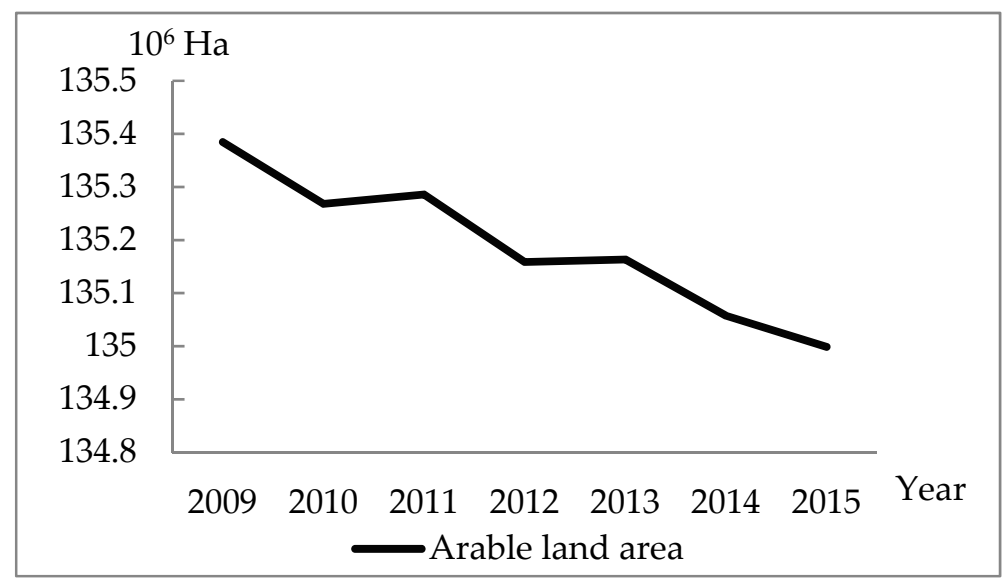

Figure 2. Changes in the area of arable land in China from 2009 to 2015.

Arable land is fundamental for food production. Recently, relevant international research mostly focuses on land requirements for food. According to a historical analysis, the developments in the land requirements for food in the Philippines are non-linear [2]. The population that a region can hold is closely related to the arable land area, production capacity, and per capita food consumption. 
Much research shows that in the future the changes of the food consumption patterns may have a greater influence on the land requirements for food than the population and it is same in China [3-5]. Hence, more and more research focuses on the changes of land requirements for food affected by food consumption patterns. Different diets may result in different land requirements for food. For an affluent diet, $60-80 \%$ more land is required than for a basic diet [6]. The consumption of animal products has an important influence on the land requirements for land. In the UK, more than $70 \%$ of the land requirements for food are related to the consumption of animal products [7]. Increasing meat in the diet results in increasing per capita land requirements [8]. Various factors affect land requirements for meat production and different meat production by pigs and beef cattle also have different land requirements [9].

Generally, when an economy grows, per capita food consumption changes [10]. The change, which is characterized by less direct grain consumption and more indirect grain consumption (i.e., animal food consumption), is happening in China. This requires China to maintain an adequate amount of arable land in order to achieve the goal of a good harvest and to ensure food security. However, what is the adequate amount? Relevant research attracts much attention from the scholars. Some researchers have analyzed and predicted arable land demand at different scales in all of China [11,12], in a province $[13,14]$, in a city $[15-17]$, or in a county $[18,19]$. In the existing studies, the main methods have included mathematical models such as the Gray-Markov combinatorial model and methods based on different objectives, such as the demand of different departments, i.e., food security, the sustainable development of regional society, economy, ecology, and even multiple objectives [20,21]. Furthermore, some scholars used several methods at the same time, analyzed the results, and then drew conclusions [22]. Some scholars particularly analyzed changes in residents' dietary patterns and took into account those possible changes while forecasting arable land demand [23,24].

However, international grain trade liberalization makes it possible to properly import grain for forage and industry currently. The existing research does not consider the situation in which the social economy, agricultural production, the people's diet, and domestic and international markets vary constantly. China is about to optimize its national territory spatial planning. It is one of the important contents to forecast arable land demand in this planning. In this study, we forecast the amount of arable land we must protect for food security in China in 2030 (short term) and 2040 (long term).

\section{Materials and Methods}

\subsection{Data}

We used the available data in China statistical yearbooks, the platform for sharing the results of the second National Land Resource Survey of China, China's land and resources statistical yearbooks from 2001 to 2016, the results of the Investigation and Assessment of Arable Land Quality Grade in China in 2015 and Chinese agricultural development reports in 2016. The data include grain yield, grain imports and exports, arable land quantity and quality, per capita consumption of major foods, population, grain yield per unit area, crops, and grain sown area. Based on the caliber of the statistics available, the grain in this study includes cereals (rice, wheat, corn and so on), beans, and tubers.

\subsection{Methods}

Arable land demand depends on the aggregate grain demand and the arable land productivity. The aggregate grain demand, which must be produced domestically, is related to the population size, per capita grain demand, and self-sufficiency ratio. The arable land productivity is related to the grain yield per unit area, the multiple cropping index and crop planting structure. Based on the above analysis, the detailed formula is as follows:

$$
S=\left(A \times G_{p} \times P\right) /(E \times R \times U)
$$


where $S$ is the arable land demand. $A$ is the grain self-sufficiency ratio. $G_{p}$ is per capita grain demand. $P$ is the national population. $E$ is the multiple cropping index. $R$ is the ratio of grain to crop sown area. $U$ is grain yield per unit area.

The methods and results of predicting the above six factors are as follows.

\subsubsection{Population}

China is the most populous country. Figure 3 shows that the population in China has increased year after year. China had a population of 1.375 billion in 2015, which was approximately 0.1 billion more than in 2000. Therefore, over the past 15 years, the national population has achieved an annual increase of 7 million people. However, the population growth rate has fluctuated significantly, but overall, it has declined.

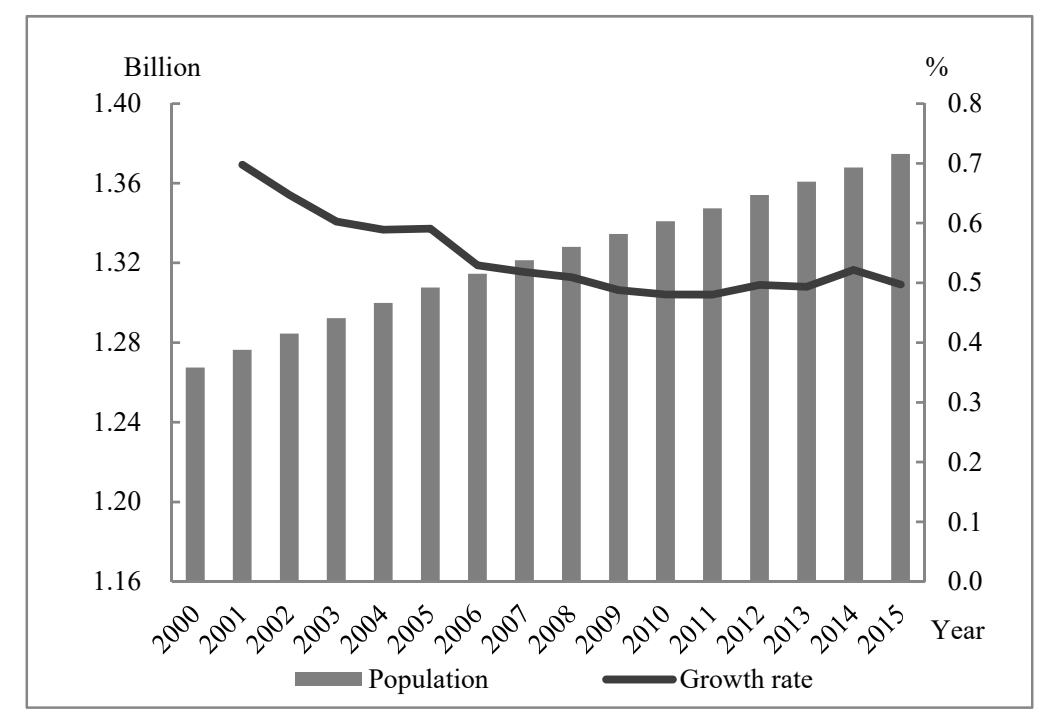

Figure 3. Changes in the national population and its growth rate from 2000 to 2015.

Why has this fluctuation occurred? Over the past few years, with the rapid development of the social economy, the levels of urbanization, healthcare, and education continue to increase, which all affects the national population. Specifically, while the economy develops and residents' incomes increase, more people are willing to have more babies. On the other hand, though, the stress from work, the rising home prices, and cost of education restrain some people from having children, especially low-and middle-income earners. As the cultural and educational level rises, the average marriage age increases and eugenics receive more attention. Some people are more willing to spend their limited income on limited kids and to raise them to be excellent. Moreover, advances in medical technology have also undoubtedly directly affected the birth and death rates. Thus, it can be seen that the population is affected by many factors.

Many scholars and institutions have analyzed and predicted China's population prospects. Most results show that the population will peak around 2030, at which point the population should actually begin to decrease [12,25-27]. The National Population Development Plan (2016-2030) predicts that the population of China will peak at 1.45 billion in 2030 and then will fall steadily [25]. The 2019 Revision of World Population Prospects predicts China will have 1.464 billion residents in 2030 and 1.449 billion in 2040 [26]. In this study, we choose the results in the 2019 Revision of World Population Prospects by the Population Division of the Department of Economic and Social Affairs of the United Nations Secretariat as the prediction of the national population. 


\subsubsection{Per Capita Grain Demand}

Previous research has shown that in the near future changes in food consumption patterns rather than population growth would be the most important variable for total land requirements for food [28]. In China, the changes are apparent (Figure 4). By comparison, the diet of rural people is different from that of urban people. The grain consumption of rural people is much higher than that of urban people, although it is decreasing. The consumption of aquatic products, meat, eggs, milk, and so on of rural people is much lower than that of urban people, although it is increasing. At the national level, the meat consumption in 2015 is 1.7 times as much as that in 2000. Generally, with the rapid urbanization in China, per capita grain consumption is declining and animal food consumption is increasing, which means that the grain for animal feed and the total grain consumption are both increasing.

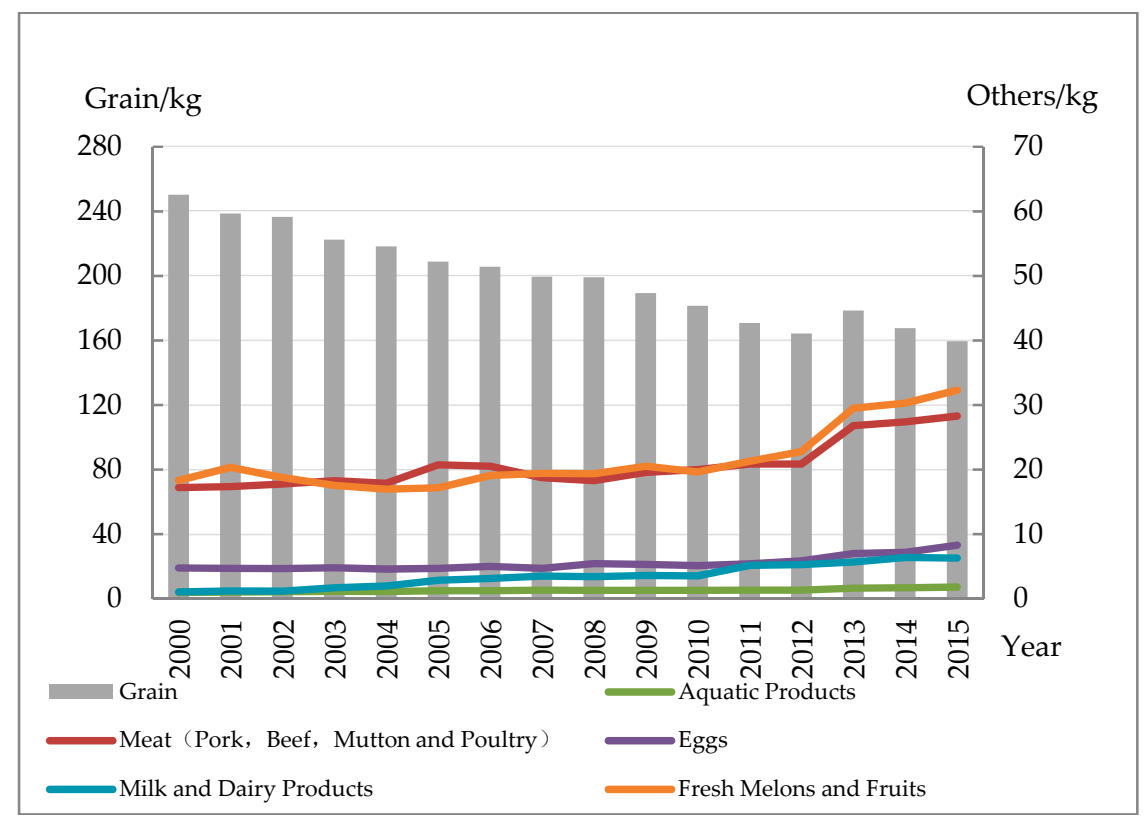

(a) Rural

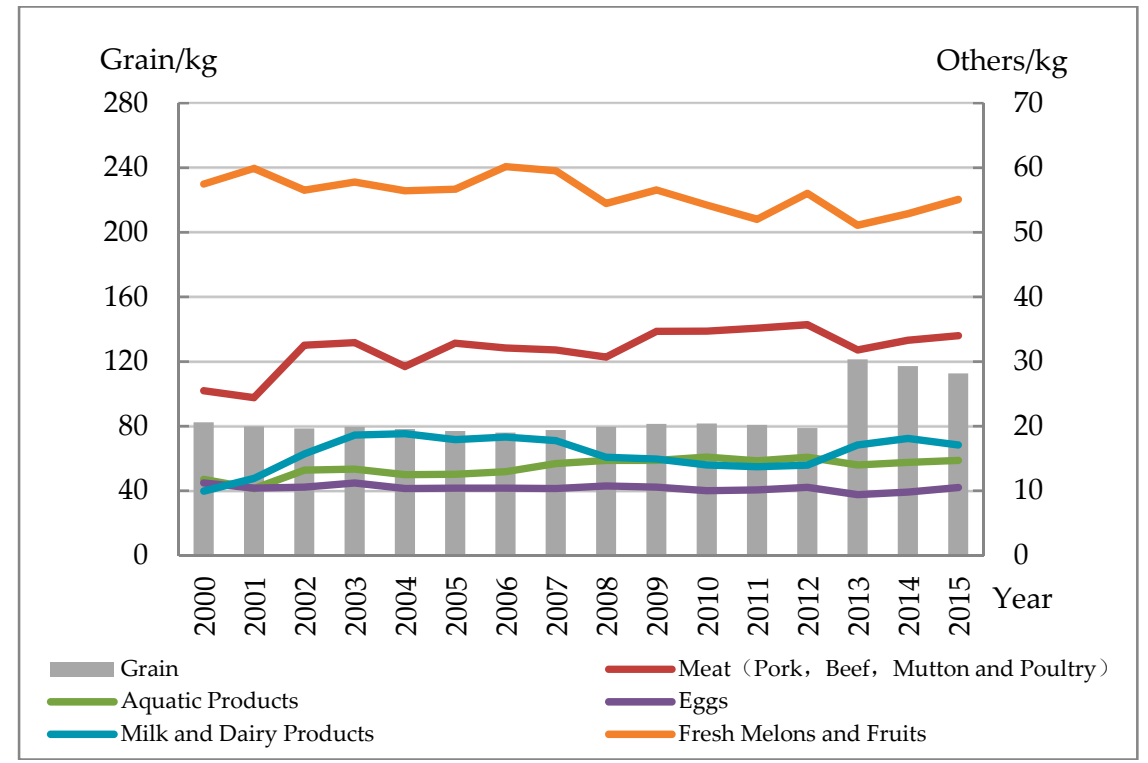

(b) Urban

Figure 4. Changes in per capita consumption of major foods in rural (a) and urban (b) households from 2000 to 2015. 
The changes, especially meat consumption, draw some scholars' attention. Zhang et al. thinks the recent trend of rising income may lead to increased meat consumption in the near future [29]. Chao et al. predicts that per capita meat consumption will increase to $85 \mathrm{~kg}$ per year in 2030 and more than $100 \mathrm{~kg}$ per year in 2040, which is still lower than that in some western developed countries [30]. However, it is not necessarily, as the dietary pattern in China has long been different from other western countries. The Chinese Dietary Guidelines recommend that meat consumption should be $40-75 \mathrm{~g}$ per capita per day. More and more Chinese people also recognize that eating too much meat could lead to some diseases, such as obesity and cardiovascular disease. Besides, some scholars predict the grain demand for different uses. They analyze and predict per capita grain demand and their outcomes differ from each other because of the different models and parameters they use. Xin et al. predicts that the demand for food and feed grain will be $386.5 \mathrm{~kg}$ per capita per year in 2030, which is driven by dietary structure changes, and $551.4 \mathrm{~kg}$ per capita per year including industrial use, seed use, and wastage [31]. Li et al. predict that it will be $421.4 \mathrm{~kg}$ per capita per year for food and feed use and $546.3 \mathrm{~kg}$ per capita per year in total [32]. Lu thinks every person needs $400 \mathrm{~kg}$ of grain per year in total for subsistence and 400-600 kg for a fairly prosperous life [33]. Chen predicts that the grain demand per capita, based on the differences in nutrition supply at moderately prosperous and prosperous levels is $450 \mathrm{~kg}$ and $500 \mathrm{~kg}$ per year, respectively [34]. Considering all of the above, we predict that the total grain demand will be $420 \mathrm{~kg}$, $500 \mathrm{~kg}$, and $550 \mathrm{~kg}$ per capita per year, respectively, for subsistence, moderately prosperous, and prosperous levels in the future. Moreover, $500 \mathrm{~kg}$ per capita per year is regarded as the demand for a nutritious diet [35].

\subsubsection{Grain Self-Sufficiency Ratio}

The grain self-sufficiency ratio is an important indicator for measuring the degree of national food security. It is generally believed that a grain self-sufficiency ratio of more than 1 means full self-sufficiency, between 0.95 and 1 means high self-sufficiency, between 0.9 and 0.95 means basic self-sufficiency, and less than 0.9 means the risk will increase.

The grain self-sufficiency ratio is the ratio of grain produced by a country or a region to grain demand. Grain demand can be calculated by grain production, import, export, and storage. As it is difficult to obtain data on grain storage, grain storage is assumed to be stable or little changed. Because of the caliber of the statistics in China, the grain in this study includes cereals (rice, wheat, corn, and so on), beans, and tubers. The Food and Agriculture Organization (FAO) of the United Nations usually counts cereal, which is international. Therefore, in this section, we also analyze the cereal self-sufficiency ratio to determine the degree of staple grain self-sufficiency, which is more comparable internationally. Cereals here mainly include wheat, rice, and corn. However, it is clear that even if the self-sufficiency ratios that are calculated are inconsistent because they are based on statistics of varying calibers, they essentially reflect the status of dependence on external grain and food security in China.

Figure 5 shows that the grain self-sufficiency ratio declined from 2000 to 2015 and has been less than 0.90 since 2012. In other words, grain security has been somewhat put at risk. Additionally, the cereal self-sufficiency ratio was more than 0.98 , even though it was decreasing. We have maintained high cereal self-sufficiency since 2000 . 


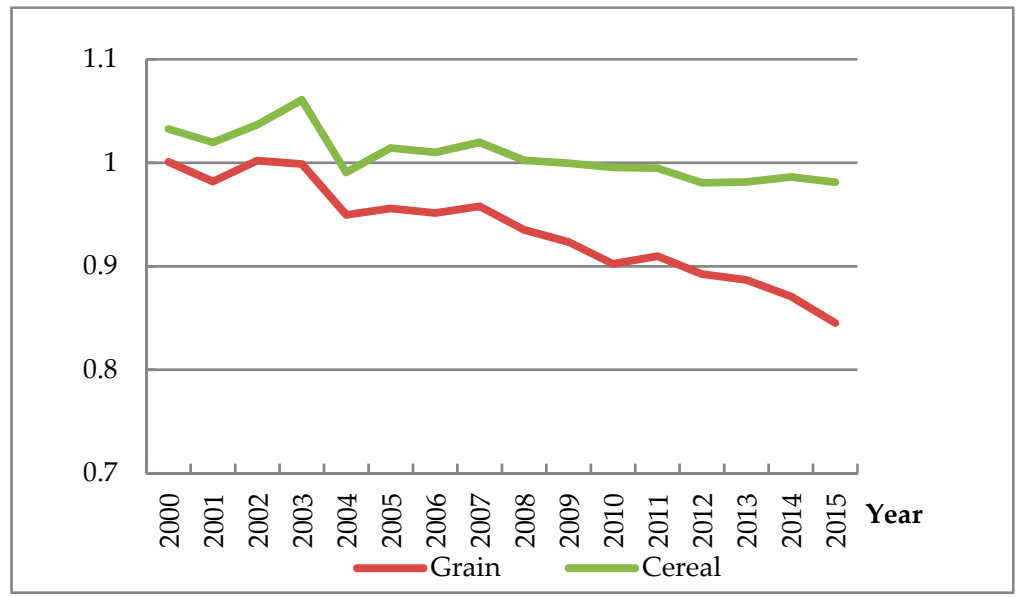

Note: Grain includes cereals, beans, and tubers; Cereal includes rice, wheat, and corn.

Figure 5. Changes in grain and cereal self-sufficiency ratio from 2000 to 2015.

Traditionally, it is stressed that the grain self-sufficiency ratio should be more than 0.95 to ensure food security in China. However, at present, it is costly to maintain such a high self-sufficiency ratio. The overuse of groundwater results in land subsidence and the overuse of pesticide, fertilizer, and plastic film results in arable land pollution, which increase the pressure on domestic resources and environment. Because of global economic integration, we can make full use of the international market to import an appropriate amount of grain. There is no doubt that this approach is a feasible way to guarantee a sufficient supply and reduce the pressure on resources such as arable land and water. However, it is clear that the international market is affected by price, politics, energy, finance, and so on. The increase of grain imports means that the impacts of the international market will also increase, which will threaten food security. Thus, it needs to be stressed that we must not be too dependent on the international market. From this perspective, our strategic option to ensure food security should be to adjust the grain self-sufficiency ratio by increasing domestic production and importing appropriately. We should be entirely self-sufficient with regard to grain for subsistence, which is actually a very basic need. A moderate increase in the imports of grain for feed and industry should be allowed. This is also recognized by many scholars that China should adjust the food security strategy in the current situation [36-38].

Hence, in this study, the grain self-sufficiency ratio is forecasted based on the different purposes of grain consumption and their respective self-sufficiency ratios. Generally, the grain is for food, feed, industry, and seed. Because the grain for seed is little, it is not taken into account. The detailed formula is as follows:

$$
A=R_{r} \times A_{r}+R_{f} \times A_{f}+R_{i} \times A_{i}
$$

where $A$ is the grain self-sufficiency ratio; $R_{r}, R_{f}, R_{i}$ are respectively the ratio of grain for food, feed, and industry; $A_{r}, A_{f}, A_{i}$ are the self-sufficiency ratio of grain for food, feed and industry.

At present, the proportion of grain for food, feed, and industry in China is about 4:2:1 [39]. According to the changes in per capita consumption of major foods (Figure 4), the grain for food is declining and the grain for feed is increasing. The change will continue in the near future and the proportion of grain for food, feed and industry in China is predicted to be $45 \%: 35 \%: 20 \%$ [11,40]. Based on the above consideration, three possible scenarios are set up: The grain self-sufficiency ratio is on (1) a high level (0.95), (2) a middle level (0.90), and (3) a low level (0.85). In the first scenario, the grain self-sufficiency ratio is 0.95 . We are fully self-sufficient for food, highly self-sufficient for feed, and basically self-sufficient for industry. In this scenario, the negative impact of international trade on our grain supply will decrease, but there will probably be more pressure on domestic resources and environment. In the second scenario, the grain self-sufficiency ratio is 0.90 . We are highly self-sufficient 
for food and basically self-sufficient for feed. Since the self-sufficiency of grain for industry is 0.80 , the grain for industry partly relies on international trade. In this scenario, there is a basic food security and the pressure on arable land, water, and other resources is slightly decreased. In the third scenario, the grain self-sufficiency ratio is 0.85 . We are still basically self-sufficient for food. Since the self-sufficiency ratios of grain for feed and industry are both 0.80 , we will face risks because of international market uncertainties. However, this scenario will effectively reduce pressure on agricultural resources and improve the environment.

\subsubsection{Grain Yield per Unit Area}

Grain yield per unit area represents the arable land productivity, which is influenced by natural environments, agricultural resource efficiency, science and technology, policies, markets, and so on. Over the past several years, grain yield per unit area has shown an increasing trend with fluctuations (Figure 6). The grain yield per unit area increased by $28.7 \%$ from $4261 \mathrm{~kg} / \mathrm{ha}$ in 2000 to $5483 \mathrm{~kg} / \mathrm{ha}$ in 2015 , as some limitations of agricultural production have been overcome recently.

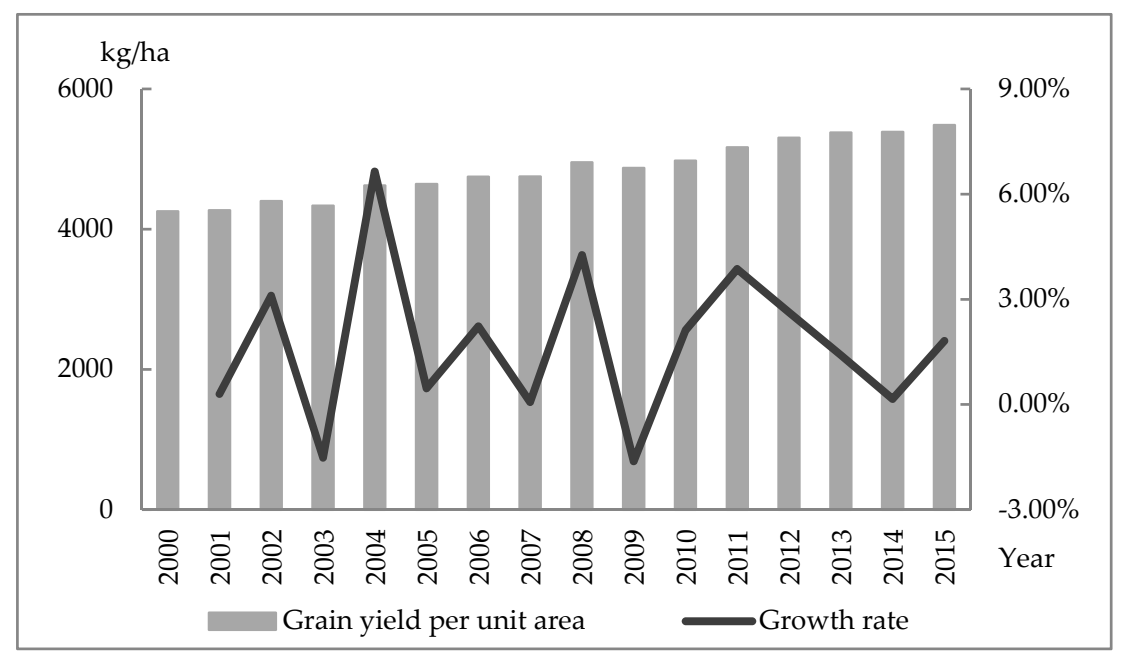

Figure 6. Changes in grain yield per unit area and its growth rate from 2000 to 2015.

Grain yield per unit area is affected by both natural and anthropic factors such as climate, soil, plant diseases, insect pests, irrigation, fertilization, and so on. Among them, the impacts of climate changes on grain productivity cannot be ignored. Because of regional differences in China, the impacts are obviously different. The negative impacts are greater than the positive in the south of China, which is opposite in the north [41]. Moreover, the advances in agricultural science and technology greatly promote the grain productivity. The uncertainty of these factors makes it difficult to predict the grain yield in the future. In this study, it is assumed that the negative impacts of climate change can be reduced by the advances of agricultural science and technology in the future. The grain yield per unit area is still potential but limited. According to the law of diminishing marginal returns of production factors, the marginal product first increases and then decreases with the increase of factor inputs. Similarly, when grain yield per unit area is increasing and closed to its potential, the growth rate of grain yield per unit area will gradually decrease [42,43]. The changes in the grain yield per unit area in China are consonant with this rule. Refer to the relevant research [44] and establish the decay model:

$$
\begin{gathered}
Y_{t}=\ln \left(U_{q}-U_{t}\right)=-i t+j \\
U_{t}=U_{q}-e^{-i t+j}
\end{gathered}
$$


where $U_{q}$ is the potential grain yield per unit area; $U_{t}$ is the grain yield per unit area in the year $t$; $U_{q}-U_{t}$ is the promotion potential grain yield per unit area; $i$ and $j$ are both the model parameters; $t$ is the year (the starting year is 1 ).

According to the grain yield per unit area of the high-yielding demonstration areas in China, it can increase to $9100 \mathrm{~kg} / \mathrm{ha}$, which is also the model-estimated average yield potential in different countries and regions $[45,46]$. Hence, in this study, $U_{q}$ is set at $9100 \mathrm{~kg} / \mathrm{ha}$. The sample data is the grain yield per unit area from 2000 to 2015 . The results are as follows:

$$
\begin{gathered}
Y_{t}=\ln \left(9100-U_{t}\right)=-0.0203 t+8.5241\left(\mathrm{R}^{2}=0.9732\right) \\
U_{t}=9100-e^{-0.0203 t+8.5241}
\end{gathered}
$$

Then, it is predicted that the grain yield per unit area in 2030 and 2040 are $6417 \mathrm{~kg} / \mathrm{ha}$ and $6910 \mathrm{~kg} / \mathrm{ha}$, respectively.

\subsubsection{Multiple Cropping Index}

The multiple cropping index, the ratio of crop sown area to arable land area, reflects the development of crop production and arable land use efficiency. In recent years, the comparative advantage of agriculture has been low so that the enthusiasm of farmers to grow grain is affected. At the same time, some regions have tried rotational and fallow farming to improve soil fertility, which results in the decline of the multiple cropping index, especially in plains. Nationally, the multiple cropping index increased from 2000 to 2008 and from 2009 to 2015, mostly between 1.2 and 1.3 (Figure 7). The change is due to the difference between the first and second National Land Resource Survey of China.

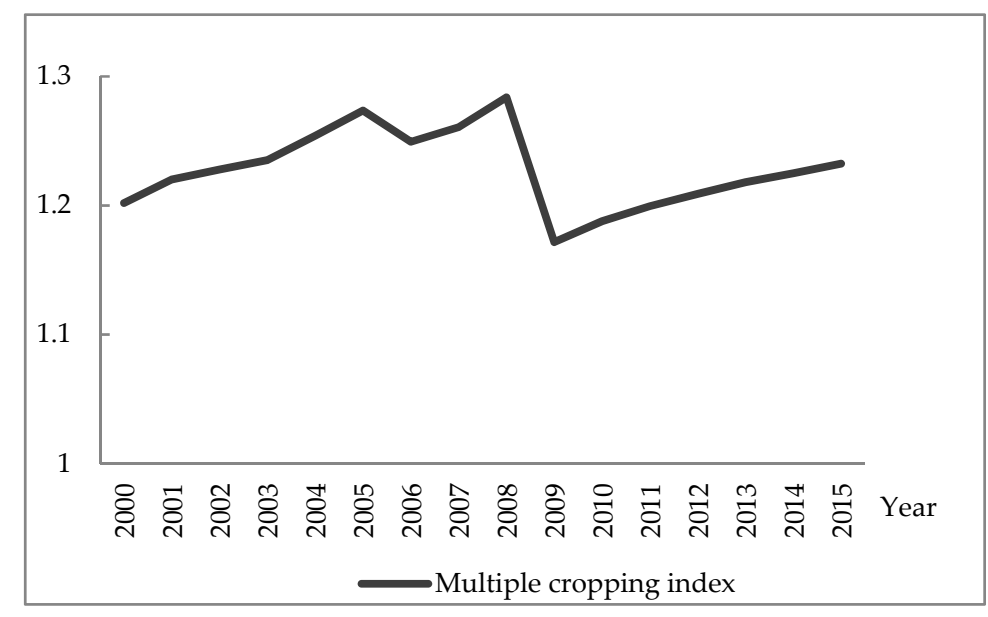

Figure 7. Changes in the multiple cropping index from 2000 to 2015.

With the population increasing and arable land decreasing, developing multiple cropping to improve the index is an important way to increase grain production and ensure food security in China. In the future, we should focus on overcoming the key obstacles to improving the quality of low-and medium-grade arable land by land consolidation, the construction of high-standard farmland, and the improvement of irrigation systems; therefore, the multiple cropping index will increase to a certain extent. Yet what is the potential multiple cropping index in China? Many scholars have researched it and the results are mostly between 1.75 and 2.0 [47-49]. However, the above results are theoretical values and cannot be achieved actually, because some of the arable land is uncultivated. When considering the pressure on resources and the environment, we should develop a resource-saving and environment-friendly multiple cropping system. By analyzing the changes in recent years and considering future policy guidance, we predict that, in the future, China's multiple cropping index will rise gradually to a higher historical level, reaching 1.3. 


\subsubsection{Ratio of Grain to Crop Sown Area}

The ratio of grain to crop sown area directly reflects the production structure of China's crop farming, which is influenced by many factors such as labor productivity, agriculture policy guidance, and the fluctuation of the agricultural products market (such as demand and price). The changes in the ratio of grain to crop sown area from 2000 to 2015 are shown in Figure 8. From 2000 to 2003, the ratio declined from 0.69 to 0.65 . However, it then gradually rose from 0.65 in 2003 to 0.69 in 2006.Since then, the ratio has been hovering at approximately 0.68 with little change.

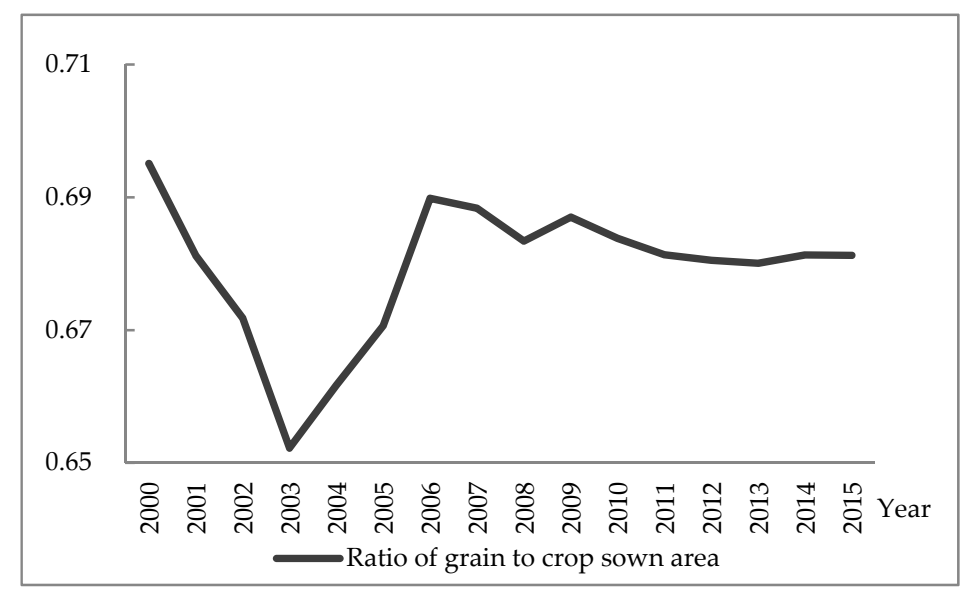

Figure 8. Changes in the ratio of grain to crop sown area from 2000 to 2015.

Stabilizing the cultivated grain area and proportion is also an important way to ensure food security. China's "No.1 Central Document" in 2012 clearly stated that every effort should be made to stabilize the grain sown area, expand the production of scarce varieties, and focus on improving yield and quality. Under the guidance of relevant departments, the grain production ratio has gradually stabilized with the adjustment and optimization of the agricultural structure. Though the income from planting cash crops is higher than that from planting grain, the subsidy policy will be improved gradually in the future to motivate farmers to grow grain. Thus, the proportion of grain will be relatively stable in the future. Correspondingly, in this study, the ratio of grain to crop sown area will remain relatively stable at approximately 0.68 .

\section{Results and Discussions}

\subsection{Arable Land Demand in Different Scenarios}

Based on the predictions of the above six factors, arable land demand in nine different scenarios calculated according to Formula 1 is shown in Table 1.

Table 1. Arable land demand in different scenarios. Unit: million ha.

\begin{tabular}{cccc}
\hline Per Capita Grain Demand & Grain Self-Sufficiency Ratio & $\mathbf{2 0 3 0}$ & $\mathbf{2 0 4 0}$ \\
\hline \multirow{3}{*}{ Subsistence } & High & 103.00 & 94.65 \\
& Middle & 97.57 & 89.67 \\
& Low & 92.15 & 84.68 \\
\hline \multirow{3}{*}{ Moderately prosperous } & High & 122.61 & 112.68 \\
& Middle & 116.16 & 106.75 \\
& Low & 109.71 & 100.82 \\
\hline \multirow{2}{*}{ Prosperous } & High & 134.88 & 123.94 \\
& Middle & 127.78 & 117.42 \\
& Low & 120.68 & 110.90 \\
\hline
\end{tabular}


Since the population will reach its peak in 2030 and the grain yield per unit area will be lower than that in 2040, the pressure to maintain sufficient arable land in 2030will be greater. With the continuous development of the social economy and the growth in people's living standards, the prediction of arable land demand, considering only subsistence, is too low. If we take it as the "red line" (the minimum requirement) for food security that we must protect, the number could be too optimistic to protect sufficient amounts of arable land. This approach also may lead to rapid loss of arable land, which will threaten the food security of our country. As per capita grain demand on the prosperous level is $10 \%$ higher than that on the moderately prosperous level, the arable land demand under the circumstances is obviously so high that we will be under enormous pressure to protect resources and the environment. Nevertheless, on a moderately prosperous level, which is also regarded as the demand for a nutritious diet, if we maintain the current self-sufficiency ratio, the arable land demand is 109.71 million ha in 2030 and 100.82 million ha in 2040. If the grain self-sufficiency ratio increases to 0.9, the arable land demand is 116.16 million ha in 2030 and 106.75 million ha in 2040. In these two situations, having a nutritious and healthy diet and making full use of international resources and markets are both taken into account. The outcomes are more referential.

According to the Chinese government, China needs to pledge to protect a minimum of 120 million ha of arable land as the "red line" for food security, which is a slightly higher than the results in this study. The main reason lies in that the current arable land productivity retains potential, the quality of some arable land is of low-and medium-grade and $0.01 \%$ of arable land is destroyed by disasters annually. Thus, at present, the "red line" is still pledged to protect.

\subsection{Challenges of Food Security and Protection of Arable Land}

Food security in China attracts many scholars from all over the world due to the challenges of a huge population and limited arable land. At present, overuse of surface water, declining groundwater levels, and water pollution are threatening the sustainability of China's agricultural production [50]. The overexploitation of groundwater results in land subsidence. Water, arable land, and air pollution threaten the grain productivity and quality. The food market is facing the pressures of domestic and international market competition. At present, in China, the strategic planning of grain import and export trade is still not clear enough and the adaptability to changes in the international market is deficient. At the same time, because of the structural contradiction between domestic supply and demand, some crops are highly dependent on the import [51]. From the foregoing, in the near future, the national population will continue to increase and the population structure and the dietary pattern will gradually change, which will lead to increasing food demand. With the income increasing, the residents pursue a better life, which means they will focus on both food quantity and quality. It can be argued that food security in China is facing all kinds of challenges.

Arable land, as a strategic resource of human existence and development, is basis of food security. Recently, with the rapid development of industrialization and urbanization, a large number of arable land was occupied and contaminated. There are serious concerns about the quality of arable land-whether its ability can supply future generations with enough food. As reserve arable land in China is limited, protection of arable land is central to food security in China in the future.

\subsection{ApproachesTowards Food Security and Protection of Arable Land}

To ensure food security in China, the basic principle is to rely on the domestic production chiefly and import appropriately. The key is to call for a sound food demand, import in an appropriate proportion, and improve the productivity. In recent years, the real per capita grain consumption in China is greater than per capita grain demand in the balance dietary pattern [52], which increases the pressure on protection of arable land. Hence, the residents should be guided to cultivate sound food consumption habits with the goal of nutrition and health in order to control per capita grain demand. At the same time, food security strategy should be adjusted appropriately. The international market and resources should be made full use of to relieve the pressure on domestic resources and 
environment. China's "No.1 Central Document" in 2019 stated that China should proactively increase the imports of the agricultural products in short supply. The guidelines should be drawn up that how much should be imported, what are the sustainable channels and how to respond to the negative effect on domestic agricultural production. Thus, the strategic planning of grain import and export trade should be made to enhance the adaptability to changes in the international market. In addition, the agricultural productivity in China should be improve constantly by the improvement of agricultural production technology and the protection of arable land.

"Trinity comprehensive protection of quantity, quality and ecology of arable land" is advocated in China. It involves a series of activities to maintain and improve the production, ecological, and life functions of arable land [53]. At the same time, the mission to protect arable land is clear-we should maintain the quantity, improve the quality, and protect arable land ecosystems. The key to maintaining quantity is to protect arable land, particularly high standard basic farmland, against being occupied by urban expansion and to increase arable land by rural land consolidation. What is central to the quality is to improve that of low-and medium-grade arable land, which China will increasingly rely on to feed itself [54]. According to the national plan for land consolidation (2016-2020), from 2011 to 2015 , land consolidation raised one grade of the quality of 35.3 million ha low-and medium-grade arable land, whose grain productivity rose by 37 million tons. If the low-and medium-grade arable land, $70 \%$ of arable land, could be consolidated, the grain productivity could increase by about 100 million tons accordingly. This shows the potential is still great. It is also effective to fertilize, rotate, and leave fallow the arable land rationally. In addition to improving the quality of arable land itself, water and air pollution should be controlled to reduce the negative impacts on the arable land quality and grain productivity. Further, arable land quality dynamic monitoring system should be established. In order to protect the stability and health of the arable land ecosystem, conservation tillage should be more used. Ecological compensation for arable land should be refined to enhance the enthusiasm of farmers to protect the arable land.

\section{Conclusions}

In this paper, the changes in national population, residents' food consumption, grain yield per unit area, self-sufficiency ratio, multiple cropping index, and ratio of grain to crop sown area from 2000 to 2015 were analyzed. In addition, we predicted the future. On this basis, we forecasted the arable land demand in nine possible situations. The results show that the population will reach its peak in 2030 and will be smaller in 2040.The yield per unit area will gradually increase with the development of agriculture science and technology. Therefore, the arable land demand in 2030 will be greater than that in 2040. After 2030, the pressure may be reduced due to the declining population and increasing production capacity. It is also effective to reduce the pressure to guide residents to have a nutritious and healthy diet and make full use of international resources and markets.

Judging from the current situation of China's economic and social development, in the near future, the total population will continue to increase, and the population structure and the dietary pattern will gradually change, which will lead to increasing food demand and effect food security. There are serious concerns about decreasing quantity and worrying quality of arable land. Therefore, food security and arable land protection in China will still face many challenges in the future.

However, the Chinese should hold the rice bowl firmly in our own hands. It needs to be emphasized that maintaining sufficient arable land is still crucial to ensuring food security. The "red line", 120 million ha of arable land should be firmly defended. By simultaneously protecting the quantity, quality, and ecology of arable land we can better protect Chinese arable land and ensure food security.

Author Contributions: A.C. collected the data, analyzed the data and wrote the manuscript. H.H. helped collect the data and advised and helped in the process of paper writing. J.W. helped carry out the calculations. M.L. and Q.G. provided suggestions. J.H. provided valuable suggestions and support. 
Funding: This work was supported by the National Key Technology Research and Development Program of the Ministry of Science and Technology of China (No. 2015BAD06B01) and the National Nature Science Foundation for Distinguished Young Scholars of China (No. 51709274).

Conflicts of Interest: The authors declare no conflict of interest.

\section{References}

1. Brown, L.R. Who Will Feed China? Wake-up Call for a Small Planet; London England Earthscan Publications: London, UK, 1995.

2. Kastner, T.; Nonhebel, S. Changes in land requirements for food in the Philippines: A historical analysis. Land Use Policy 2010, 27, 853-863. [CrossRef]

3. Gerbens-Leenes, P.W.; Nonhebel, S.; Ivens, W. A method to determine land requirements relating to food consumption patterns. Agric. Ecosyst. Environ. 2002, 90, 47-58. [CrossRef]

4. Kastner, T.; Rivas, M.J.I.; Koch, W.; Nonhebel, S. Global changes in diets and the consequences for land requirements for food. Proc. Natl. Acad. Sci. USA 2012, 109, 6868-6872. [CrossRef] [PubMed]

5. Nath, R.; Luan, Y.; Yang, W.; Yang, C.; Chen, W.; Li, Q.; Cui, X. Changes in Arable Land Demand for Food in India and China: A Potential Threat to Food Security. Sustainability 2015, 7, 5371-5397. [CrossRef]

6. Ibarrola-Rivas, M.J.; Granados-Ramirez, R. Diversity of Mexican diets and agricultural systems and their impact on the land requirements for food. Land Use Policy 2017, 66, 235-240. [CrossRef]

7. De Ruiter, H.R.; Macdiarmid, J.I.; Matthews, R.B.; Smith, P. Assessing land requirements associated with UK food consumption: Implications for food security and environmental sustainability. Proc. Nutr. Soc. 2015, 74, E119. [CrossRef]

8. Peters, C.J.; Wilkins, J.L.; Fick, G.W. Testing a complete-diet model for estimating the land resource requirements of food consumption and agricultural carrying capacity: The New York State example. Renew. Agric. Food Syst. 2007, 22, 145-153. [CrossRef]

9. Elferink, E.V.; Nonhebel, S. Variations in land requirements for meat production. J. Clean. Prod. 2007, 15, 1778-1786. [CrossRef]

10. Gerbens-Leenes, P.W.; Nonhebel, S.; Krol, M.S. Food consumption patterns and economic growth. Increasing affluence and the use of natural resources. Appetite 2010, 55, 597-608. [CrossRef]

11. Ma, Y.H.; Niu, W.Y. Forecasting on Grain Demand and Availability of Cultivated Land Resources Based on Grain Safety in China. China Soft Sci. 2009, 11-16. [CrossRef]

12. Zhao, Y.Y.; Wang, J.; Zhang, L.; Jiang, L.L. Analysis of arable land requirement for protecting the self-supply of grains under new food security policy. J. Arid Land Resour. Environ. 2015, 1-6. [CrossRef]

13. Xie, S.C.; Zhu, J.J.; Song, Y.Y. Forecast of the demand of cultivated land in Ningxia based on food security consideration. Res. Agric. Mod. 2016, 663-670. [CrossRef]

14. Qiao, R.; Li, Y.; Cai, Y. Prediction of the cultivated land demand based on Logistic Equation-A case of Zhejiang Province, China. Asian Agric. Res. 2009, 1, 49-52.

15. Zhang, X.; Zou, Z.; Liu, H. Study on the Forecasting of Cultivated Land Demand Based on Gray-Markov Combinatorial Model; Zhu, K., Zhang, H., Eds.; Aussino Academic Publishing House: Marrickville, Australia, 2009; pp. 1617-1622.

16. Wang, R.Y.; Lin, Y.L. The Forecasting of Cultivated Land Demand Based on Gray-Markov Combinatorial Model; Han, L.S., Gipouloux, F., Zhang, H., Eds.; Aussino Academic Publishing House: Marrickville, Australia, 2009; pp. 251-255.

17. Zhen, L.; Cao, S.; Cheng, S.; Xie, G.; Wei, Y.; Liu, X.; Li, F. Arable land requirements based on food consumption patterns: Case study in rural Guyuan District, Western China. Ecol. Econ. 2010, 69, 1443-1453. [CrossRef]

18. Zhang, J.; Li, J.F. Study on the Forecasting Methods of the Demand of Arable Land. J. Anhui Agric. Sci. 2006, 1204-1206. [CrossRef]

19. Wang, W.M.; Pan, W.Z. Study on the Arable Land Demand. Resour. Dev. Mark. 1988, 4, 7-10.

20. Xiao, G.Q.; Wang, W.H.; Zhang, D.J.; Dou, S. Demand Prediction for Arable Land in the New Round of Land Use Planning-Taking Jilin Province as an Example. Nat. Resour. Econ. China 2009, 23-25. [CrossRef]

21. Cai, Y.M.; Zhang, W.X.; Liu, Y.S. Forecasting and Analyzing the Cultivated Land Demand based on Multi-Objectives in China. Resour. Sci. 2007, 134-138. [CrossRef] 
22. Zhu, X.L.; Zhou, W.L. Study on the Forecasting Methods of the Demand of Arable Land in Land Use Planning. J. Southwest Agric. Univ. 2010, 5-10. [CrossRef]

23. Gao, L.W.; Xu, Z.R.; Cheng, S.K.; Xu, S.W.; Zhang, X.Z.; Yu, C.Q.; Sun, W.; Wu, J.X.; Qu, Y.H.; Ma, J. Arable Land Requierments Related Food Consumption Pattern-A Case Study in Lhasa, Xigaze and Shannan Region of Rural Tibet. J. Nat. Resour. 2017, 32, 12-25.

24. Liu, C.X.; Wang, F. Dynamic changes in arable land requirements for food consumption in China. Chin. J. Eco-Agric. 2018, 1227-1235. [CrossRef]

25. The State Council of the People's Republic of China. The National Population Development Plan (2016-2030); The State Council of the People's Republic of China: Beijing, China, 2016.

26. United Nations, Department of Economic and Social Affairs, Population Division. Probabilistic Population Projections Based on the World Population Prospects. 2019. Available online: http://population.un.org/wpp/ (accessed on 1 July 2019).

27. Meng, L.G.; Li, C.L.; Hu, G. Predictions of China's Population Structure Based on the PDF Model. China Popul. Resour. Environ. 2014, 24, 132-141. [CrossRef]

28. Gerbens-Leenes, P.W.; Nonhebel, S. Consumption patterns and their effects on land required for food. Ecol. Econ. 2002, 42, 185-199. [CrossRef]

29. Zhang, H.F.; Wang, J.; Martin, W. Factors affecting househ olds' meat purchase and future meat consumption changes in China: A demand system approach. J. Ethn. Foods 2018, 5, 24-32. [CrossRef]

30. Chao, H.S.; Tian, X.; Yu, X.H. Meat consumption structure, feed security, and grain security: Implication for the "supply-side reform" in agriculture. Res. Agric. Mod. 2017, 38, 737-745. [CrossRef]

31. Xin, L.J.; Wang, J.Y.; Wang, L.X. Prospect of per capita grain demand driven by dietary structure change in China. Resour. Sci. 2015, 1347-1356.

32. Li, J.; Li, Z. Physical limitations and challenges to Grain Security in China. Food Secur. 2014, 6, $159-167$. [CrossRef]

33. Lu, Q. Some Issues on the Trlationship Between Land Resources Developmnt Production and Food Security. Resour. Sci. 1999, 5-8. [CrossRef]

34. Chen, B.M. On the comprehensive productive capacity and food security of future agricultural resources in China. Geogr. Res. 2002, 294-304. [CrossRef]

35. Shi, Y.L.; Yu, G.R.; Wang, H.; Liu, X.T. Study on Land Ecological Security, Optimal Allocation of Soil and Water Resources and Spatial Pattern; Science Press: Beijing, China, 2017; Volume 2, p. 138.

36. Jia, S.S.; Zhang, X.H. The Realistic Logic of the Strategic Adjustment of Food Security in China under the New Situation. Price Theory Pract. 2016, 140-143.

37. Yang, W.J.; Lin, B.; Liu, Q.; Li, Q. China's New Strategy of Grain Security: “Grain Ration”, "Rice Safety” and "One Belt and One Road". World Agric. 2018, 208-214. [CrossRef]

38. Wang, Y. The Challenges and Strategies of Food Security under Rapid Urbanization in China. Sustainability 2019, 11, 542. [CrossRef]

39. Zhou, Z.J. Analysis of Current Grain Consumption Demand in China. J. Agrotech. Econ. 2015, 68-75. [CrossRef]

40. Luo, Q.Y.; Mi, J.; Gao, M.J. Research on Forecasting for Long-Term Grain Consumption Demands in China. Chin. J. Agric. Resour. Reg. Plan. 2014, 35, 1-7. [CrossRef]

41. Yin, C.J.; Li, G.C.; Gao, X. Impacts of climate change on China's grain production-Empirical analysis based on provincial panel data. J. Arid Land Resour. Environ. 2016, 30, 89-94. [CrossRef]

42. Cai, C.Z.; Chen, F.; Xu, J.; Liang, Y. Approaches to Enhance Crop's Yield Potential. Res. Agric. Mod. 2002, 465-468. [CrossRef]

43. Cai, C.Z.; Chen, F.; Sui, P.; Chen, J.S. Study on Potential Limit of Crop Yield. Chin. J. Eco-Agric. 2005, 13, $145-148$.

44. Zhu, J.W.; Zhou, L.L.; Xie, X.T. Forecasting the Promotion Potential of Grain Yield per Unit in Mid-long Term with a Decay Model: A Case Study in Henan Province. J. Nat. Resour. 2017, 32, 1627-1638. [CrossRef]

45. Liu, B.H.; Chen, X.P.; Cui, Z.L.; Meng, Q.F.; Zhao, M. Research advance in yield potential and yield gap of three major cereal crops. Chin. J. Eco-Agric. 2015, 23, 525-534. [CrossRef]

46. Chen, Y.J.; Yi, X.Y.; Fang, L.N.; Yang, R.Z. Analysis of Cultivated Land and Grain Production Potential in China. Sci. Agric. Sin. 2016, 49, 1117-1131. [CrossRef] 
47. Fan, J.L.; Wu, B.F. A Study on Cropping Index Potential Based on GIS. J. Remote Sens. 2004, 637-644. [CrossRef]

48. Shi, J.T.; Liu, M.J.; Li, J. Multicropping and Sustainable Development in Grain Production of China. Agric. Res. Arid Areas 1998, 54-60.

49. Zuo, L.; Wang, X.; Zhang, Z.; Zhao, X.; Liu, B.; Liu, F.; Yi, L. Developing grain production policy in terms of multiple cropping systems in China. Land Use Policy 2014, 40, 140-146. [CrossRef]

50. Fan, M.; Shen, J.; Yuan, L.; Jiang, R.; Chen, X.; Davies, W.J.; Zhang, F. Improving crop productivity and resource use efficiency to ensure food security and environmental quality in China. J. Exp. Bot. 2012, 63, 13-24. [CrossRef] [PubMed]

51. Tong, D.D. A Study on the Strategy of Grain Import and Export in China from the Perspective of Domestic Food Security. Reform. Strategy 2017, 33, 179-181, 185. [CrossRef]

52. Tang, H.J.; Li, Z.M. Study on Per Capita Grain Demand Based on Chinese Reasonable Dietary Pattern. Sci. Agric. Sin. 2012, 45, 2315-2327. [CrossRef]

53. Zu, J.; Hao, J.M.; Chen, L.; Zhang, Y.B.; Wang, J.; Kang, L.T.; Guo, J.H. Analysis on trinity connotation and approach to protect quantity, quality and ecology of cultivated land. J. China Agric. Univ. 2018, 23, 84-95.

54. Kong, X. China must protect high-quality arable land. Nature 2014, 506, 7. [CrossRef]

(C) 2019 by the authors. Licensee MDPI, Basel, Switzerland. This article is an open access article distributed under the terms and conditions of the Creative Commons Attribution (CC BY) license (http://creativecommons.org/licenses/by/4.0/). 